\title{
Erratum zu: Polytope mit vielen Splits und ihre Sekundärfächer
}

\section{Michael Joswig • Thilo Rörig}

Online publiziert: 22. Juni 2012

(C) Springer-Verlag 2012

\section{Erratum zu: Math Semesterber}

\section{DOI 10.1007/s00591-012-0102-9}

Leider ist im Druck dieser Abbildung ein Fehler unterlaufen. Die korrekte Fassung ist hier wieder gegeben.

Die Abbildung 1 zeigt den Sekundärfächer des regulären Fünfecks. Zu jedem Sekundärkegel ist die zugehörige Unterteilung angegeben.

Abb. 1 Sekundärfächer des Fünfecks $C_{5}$

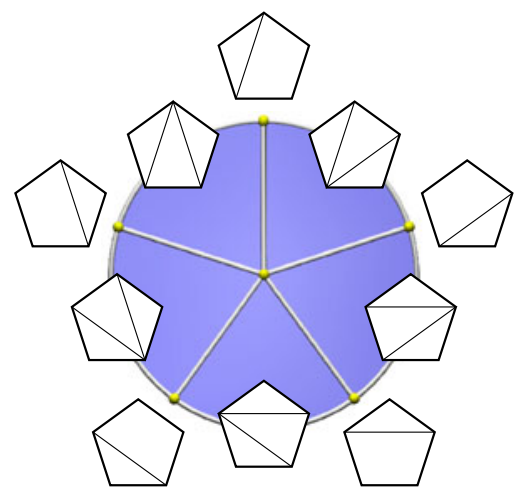

Die Online-Version des Originalartikels können Sie unter doi:10.1007/s00591-012-0102-9 finden.

M. Joswig ( $ه)$

Fachbereich Mathematik, TU Darmstadt, Darmstadt, Deutschland

e-mail: joswig@mathematik.tu-darmstadt.de

T. Rörig

Institut für Mathematik, TU Berlin, Berlin, Deutschland

e-mail: roerig@math.tu-berlin.de 